\title{
Ribulose Diphosphate Carboxylase in Thiorhodaceae
}

\author{
By R. E. HURLBERT* AND JUNE LASCELLES \\ Microbiology Unit, Department of Biochemistry, University of Oxford
}

(Received 4 July 1963)

\begin{abstract}
SUMMARY
The concentration of ribulose 1,5-diphosphate (RuDP) carboxylase, the enzyme which catalyses the conversion of ribulose 1,5 -diphosphate $+\mathrm{CO}_{2}$ to 3-phosphoglyceric acid, was partially repressed in some Thiorhodaceae organisms when these were grown on certain organic compounds. Transfer of thiosulphate-grown organisms possessing a high concentration of enzyme into growth medium containing pyruvate caused a rapid decline in carboxylase activity. In the reverse situation, pyruvate-grown organisms preferentially synthesized RuDP carboxylase when transferred to growth medium containing thiosulphate alone. The presence of thiosulphate prevented loss of carboxylase with pyruvate. The incorporation pattern of ${ }^{14} \mathrm{CO}_{2}$ into the ethanol-soluble compounds of organisms metabolizing thiosulphate alone was typical of autotrophic metabolism; most of the $\mathrm{CO}_{2}$ was fixed via the reductive pentose cycle. The pattern of incorporation of ${ }^{14} \mathrm{CO}_{2}$ by organisms metabolizing pyruvate was strikingly different in that $\mathrm{CO}_{2}$ entered the cell constituents predominantly via a carboxylation leading to a four-carbon product. However, even under the latter conditions, the RuDP carboxylase and the reductive pentose cycle appeared to operate to some extent, since phosphoglycerate was an early product of $\mathrm{CO}_{2}$ fixation. Phosphoglycerate was an early product of ${ }^{14} \mathrm{CO}_{2}$ fixation by thiosulphate-grown organisms incubated with a variety of organic substrates, showing that the carboxylase and the reductive pentose cycle could function under these conditions. The addition of thiosulphate increased incorporation of ${ }^{14} \mathrm{CO}_{2}$ into phosphate esters by pyruvate-grown organisms incubated with pyruvate. It is concluded that ribulose diphosphate carboxylase and the reductive pentose cycle function in Thiorhodaceae even when grown on organic substrates; its quantitative importance was not assessed. The synthesis of the carboxylase was influenced by the growth substrate.
\end{abstract}

\section{INTRODUCTION}

Ribulose-1,5-diphosphate (RuDP) carboxylase catalyses the formation of 3-phosphoglycerate from $\mathrm{RuDP}+\mathrm{CO}_{2}$; it is a key enzyme in the reductive pentose cycle and is present in all organisms when grown autotrophically on $\mathrm{CO}_{2}$ as sole carbon source (Quayle, 1961). In several autotrophic organisms, which are able also to grow heterotrophically, the RuDP carboxylase has been shown to be adaptive, since it is not formed when such organisms are grown with organic substrates (Quayle, 1961).

The Thiorhodaceae (purple sulphur bacteria) grow anaerobically in the light

* Present address : National Institute of Arthritis and Metabolic Diseases, National Institutes of Health, Bethesda, Maryland, U.S.A. 
either with $\mathrm{CO}_{2}$ as sole carbon source + reduced sulphur compounds as electron donor, or with organic carbon substrates (van Niel, 1941). Under the latter conditions the oxidation state of the organic molecule determines whether there is net evolution or assimilation of $\mathrm{CO}_{2}$ (Muller, 1933; van Niel, 1936). When the substrate is more oxidized than cell material the oxidation-reduction balance is maintained by evolution of $\mathrm{CO}_{2}$. With a more reduced substrate added $\mathrm{CO}_{2}$ is required for growth, and oxidation of the substrate is coupled with reduction of $\mathrm{CO}_{2}$. Under these circumstances the role of $\mathrm{CO}_{2}$ is that of a 'sink' which permits the removal of surplus reducing power (Gaffron, 1935; Stanier, 1961). RuDP carboxylase has been demonstrated in Thiorhodaceae grown in an inorganic medium and it is responsible for the synthesis of a considerable proportion of the cell carbon via the reductive pentose cycle (Fuller, Smillie, Sisler \& Kornberg, 1961). RuDP carboxylase might also have an additional function when the organisms grow with organic substrates; the carboxylase could convert $\mathrm{CO}_{2}$ to phosphoglycerate, which in turn might serve as a hydrogen acceptor for the re-oxidation of $\mathrm{NADH}^{+}$generated by oxidation of the organic substrate. Such a role has been suggested for RuDP carboxylase in the Athiorhodaceae, which require organic carbon, yet when grown anaerobically in the light form RuDP carboxylase (Lascelles, 1960b).

In the present work RuDP carboxylase was assayed in Thiorhodaceae grown on inorganic and organic media to see whether there was a correlation between its amount and its possible functions. The effect of various substrates on the rate of enzyme synthesis was also studied. The incorporation of ${ }^{14} \mathrm{CO}_{2}$ into soluble material was followed to determine whether the RuDP carboxylase actually functioned whilst the organisms were growing with different substrates.

\section{METHODS}

Organisms. Chromatium sp. strain D was obtained from Professor R. C. Fuller (Dartmouth Medical School, New Hampshire, U.S.A.). Thiopedia sp. strain PM was isolated from local mud. The purity of each culture was checked by re-isolation from single colonies. Stock cultures were kept as stabs on the thiosulphate medium described below, solidified with agar (1\%). A layer of soft paraffin wax maintained anaerobic conditions. The stabs were incubated at $32-34^{\circ}$ for $2-3$ days in front of a bank of 25-40 watt tungsten lamps. They were transferred monthly and stored at $0^{\circ}$.

Media. The salts medium used was similar to that described by Larsen (1952) for growth of Chlorobium thiosulphatophilum. It contained (g./l.): $\mathbf{N H}_{4} \mathrm{Cl}, \mathbf{1}$; $\mathrm{KH}_{2} \mathrm{PO}_{4}, 1 ; \mathrm{MgCl}_{2} .6 \mathrm{H}_{2} \mathrm{O}, 0.5 ; \mathrm{CaCl}_{2}, 0.02$; iron citrate, 0.006 ; trace salts solution (Kohlmiller \& Gest, 1951), $2 \mathrm{ml}$. For autotrophic growth with thiosulphate as electron donor, the following supplements were added as sterile solutions after autoclaving the salts medium (g./l.): $\mathrm{Na}_{2} \mathrm{~S}_{2} \mathrm{O}_{3} .5 \mathrm{H}_{2} \mathrm{O}, 3 ; \mathrm{NaHCO}_{3}, 5 ; \mathrm{Na}_{2} \mathrm{~S} .9 \mathrm{H}_{2} \mathrm{O}$, $0 \cdot 1$. Stock solutions of these compounds $(5$ or $10 \%, \mathrm{w} / \mathrm{v})$ were separately sterilized by heating $\left(121^{\circ}, 10 \mathrm{~min}\right.$.); the heated $\mathrm{NaHCO}_{3}$ solution was flushed with $\mathrm{CO}_{2}$ before use. The thiosulphate was replaced by organic substrates $(0 \cdot 005-0 \cdot 02 \mathrm{M}$, final concentration) as required. In experiments where bicarbonate was omitted, the medium was adjusted after autoclaving to $\mathrm{pH} \mathbf{7 \cdot 8 - 8 \cdot 2}$ by adding sterile $10 \mathrm{~N}-\mathrm{NaOH}$.

Growth of cultures. Media were inoculated immediately after autoclaving and cooling; each bulk culture was inoculated with 1-5 ml. of a culture grown with the 
same substrate per $100 \mathrm{ml}$. medium. The cultures were grown in completely filled, glass-stoppered bottles incubated at $30-32^{\circ}$ in front of banks of $25-40$ watt tungsten lamps.

In some experiments enzyme activities were followed in growing cultures. Organisms from $800 \mathrm{ml}$. cultures were harvested at the end of logarithmic growth or early in the stationary phase, washed in $400 \mathrm{ml}$. of salts medium without substrate, resuspended in $1 \mathrm{l}$. basal salts medium with the appropriate substrate and the suspension filled into Roux bottles. All solutions and containers were flushed with oxygen-free nitrogen before addition of organisms; the Roux bottles were closed with rubber bungs. The filled bottles of inoculated media were incubated in a glass-sided water bath at $34^{\circ}$, illuminated with 150 -watt tungsten lamps at about $10 \mathrm{~cm}$. from the centre of the bottle. Samples were removed at intervals, the bottles being re-flushed with $\mathrm{O}_{2}$-free nitrogen after each operation.

Preparation of cell-free extracts. Organisms were harvested by centrifugation, washed in one half the original culture volume of $0.05 \mathrm{M}$-tris buffer $(\mathrm{pH} \mathrm{7.5})$ and resuspended to a density equivalent to about $30 \mathrm{mg}$. dry wt. organism/ $\mathrm{ml}$. in the same buffer. Thiopedia organisms were disrupted by passage through a French pressure cell (American Instrument Co., Silver Springs, Md., U.S.A.) cooled to $0^{\circ}$. Chromatium organisms were disrupted by this method or by ultrasonic vibration as described previously (Lascelles, 1960 a). Whole organisms and debris were removed by centrifugation at $25,000 \mathrm{~g}$ for $10 \mathrm{~min}$. at $0^{\circ}$, and the supernatant fluid (equiv. 5-10 mg. protein/ml.) was used in assays of enzyme activity.

Assay of RuDP carboxylase. The method used was slightly modified from that described previously (Lascelles, $1960 \mathrm{~b}$ ). Each tube contained in a final volume of $0.5 \mathrm{ml}$.: tris buffer ( $\mathrm{pH} \mathrm{7.5}$ ), $50 \mu$ mole; $\mathrm{MgCl}_{2}, 15 \mu$ mole; L-cysteine, $2.5 \mu$ mole; $\mathrm{RuDP}$ (potassium salt), $0.3 \mu$ mole; $\mathrm{NaHCO}_{3}, 25 \mu$ mole; cell-free extract equivalent to $\mathbf{0} \cdot \mathbf{2} \mathrm{mg}$. protein. Incubation was at $37^{\circ}$ for $5 \mathrm{~min}$. and the reaction then stopped by heating the tubes for 2 min. in a boiling water bath. After centrifugation phosphoglycerate was determined in the supernatant fluid by the spectrophotometric method described by Lascelles $(1960 b)$. Controls without bicarbonate were included in each assay and the values obtained were deducted from the experimental values. One unit of enzyme is defined as that amount which catalyses the formation of $1 \mu \mathrm{m}$.-mole 3-phosphoglycerate under the standard conditions of the assay.

Incorporation of ${ }^{14} \mathrm{CO}_{2}$. Experiments were carried out at room temperature in the apparatus described by Knight (1962). Freshly harvested organisms (unwashed) were resuspended to a density equiv. $4 \mathrm{mg}$. dry wt. $/ \mathrm{ml}$. in $15 \mathrm{ml}$. volumes of a

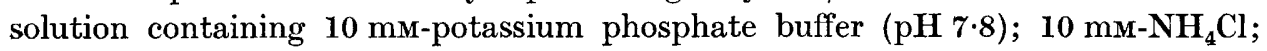
$1 \mathrm{mM}-\mathrm{MgCl}_{2}$; this salts mixture was flushed with nitrogen (oxygen-free) before suspending the organisms in it. The suspensions were flushed with nitrogen for about $3 \mathrm{~min}$. and substrate and $\mathrm{NaHCO}_{3}$ added (each $10 \mathrm{~mm}$ final concentration). Illumination was with two 40 -watt tungsten lamps $6 \mathrm{~cm}$. from the reaction vessel; a sheet of glass was held between the lamps and vessel to prevent heating. After equilibration for $15 \mathrm{~min}$. with the lights on, $\mathrm{Na}_{2}{ }^{14} \mathrm{CO}_{3}$ to a concentration of $15 \mu \mathrm{c} . / \mathrm{ml}$. was added with a hypodermic syringe, as described by Knight (1962). Samples $(0 \cdot 7-1.3 \mathrm{ml}$.) were removed at intervals up to $5 \mathrm{~min}$., and run directly into weighed flasks containing $4 \mathrm{ml}$. of a mixture of ethanol + water + acetic acid $(950+50+1$, by 
vol.). The flasks were reweighed to determine the volume of sample taken, the solid material removed by centrifugation and the clear supernatant fluid ('soluble fraction') prepared for chromatography and radio-autography as described by Hoare (1963).

The total amount of ${ }^{14} \mathrm{CO}_{2}$ fixed into the soluble and insoluble fractions of each sample was found by plating $0 \cdot 1 \mathrm{ml}$. portions, before and after centrifugation, on aluminium planchettes $\left(3 \mathrm{~cm} .{ }^{2}\right)$ containing a disc of lens tissue. These were dried after the addition of one drop of $90 \%(\mathrm{w} / \mathrm{v})$ formic acid and counted by using a mica thin end-window Geiger-Muller tube; these counts were corrected for background.

Chromatography and radio-autography. The radioactive compounds in the soluble fraction were separated by two-dimensional chromatography and identified by radio-autography by the methods described by Large, Peel \& Quayle (1961). The equivalent of one half of the original sample was used for each chromatogram. The radioactive area which remained near the origin after chromatography was designated the phosphate ester area. To identify 3-phosphoglyceric acid the material from this area was eluted and dephosphorylated with Polidase-S according to the procedure of Benson, Bassham \& Calvin (1951). After this treatment the material was subjected to two-dimensional chromatography in the same solvents used for the initial separation.

The radioactivity on the chromatograms was measured with a mica thin endwindow Geiger-Muller tube; the counts recorded are corrected for background.

Analytical methods. Protein in the cell-free extracts was determined by the method of Lowry, Rosebrough, Farr \& Randall (1951). In whole organisms metabolizing thiosulphate this method was unsatisfactory, possibly because of interference by sulphur compounds within the organisms. The protein of whole organism was therefore determined by the biuret method as follows. Samples were centrifuged and the photosynthetic pigments extracted by resuspending the pellet in acetone + methanol $(7+2$, by vol.). After centrifugation the pellet was digested for $10 \mathrm{~min}$. at $100^{\circ}$ with $2 \mathrm{ml}$. N-NaOH; $2 \mathrm{ml}$. of copper tartrate solution $\left(1.5 \mathrm{~g}\right.$. $\mathrm{CuSO}_{4} \cdot 5 \mathrm{H}_{2} \mathrm{O}+$ $6.0 \mathrm{~g}$. sodium potassium tartrate in $250 \mathrm{ml}$. water) were added to the cooled digest and the colour was read at $500 \mathrm{~m} \mu$ after $30 \mathrm{~min}$. For both methods of protein estimation crystalline bovine plasma albumin was the standard.

Pyruvate was estimated by the method of Friedmann \& Haugen (1943), and thiosulphate by titration with iodine with starch as indicator.

Spectrophotometric measurements were made with an Unicam spectrophotometer, model SP-600, or, in the case of the estimation of 3-phosphoglycerate, with an Optica recording spectrophotometer, Model CF 4.

Materials. $\mathrm{Na}_{2}{ }^{14} \mathrm{CO}_{3}$ was from the Radiochemical Centre, Amersham, Buckinghamshire. The sources of other special materials were given previously (Lascelles, $1960 a, b)$.

\section{RESULTS}

Growth of Chromatium and Thiopedia organisms on various substrates

Growth of the organisms was tested on a variety of substrates with and without bicarbonate (Table 1). With most compounds added bicarbonate was not required, presumably because the oxidation level was at least equal to that of cell material 
(Muller, 1933). Fatty acids beyond propionate were not used by either organism. Bicarbonate was needed for growth on propionate; it was not needed for growth of Chromatium on acetate, as observed previously (Losada, Trebst, Ogata \& Arnon, 1960; Fuller et al. 1961). Thiopedia used a wider variety of substrates than did Chromatium; the vigorous growth on fructose though not on other sugars is notable.

\section{Table 1. Growth of Chromatium and Thiopedia organisms on various substrates}

Cultures were incubated in completely filled, stoppered bottles ( $30 \mathrm{ml}$. volume) in the basal salts medium containing $0.01 \%$ sodium sulphide, and supplemented with the appropriate substrate (sodium salts, $0.005-0.02 \mathrm{M}$ ) and sodium bicarbonate $(0.5 \%$ ) as shown. Incubation was in the light at $30-\mathbf{3 2}^{\circ}$; cultures which showed no growth after 10 days are listed as negative $(-)$.

\begin{tabular}{|c|c|c|c|c|}
\hline \multirow{3}{*}{ Substrate } & \multicolumn{2}{|c|}{ Chromatium } & \multicolumn{2}{|c|}{ Thiopedia } \\
\hline & \multicolumn{2}{|c|}{ Bicarbonate } & \multicolumn{2}{|c|}{ Bicarbonate } \\
\hline & + & - & + & - \\
\hline Thiosulphate & + & NT* & + & NT* \\
\hline Sulphide & + & $\mathbf{N} \mathbf{T}$ & + & NT \\
\hline †Sulphur & + & $\mathbf{N T}^{\prime}$ & + & NT \\
\hline Formate & + (poor) & - & $+($ poor $)$ & - \\
\hline Acetate & + & + & + & $+($ poor $)$ \\
\hline Propionate & + & - & + & - \\
\hline Pyruvate & + & + & + & + \\
\hline Lactate & + (poor) & + (poor) & + & + \\
\hline Malate & + & + & + & + \\
\hline Fumarate & + & + & + & + \\
\hline Succinate & + & + & + & + \\
\hline$\alpha$-Oxoglutarate & + & + (poor) & - & N'T \\
\hline Fructose & - & NT & + & + \\
\hline Glycerol & - & $\mathbf{N T}$ & + & + \\
\hline Glyoxylate & - & NT & + & + \\
\hline Glycollate & - & $\mathrm{NT}$ & + & + \\
\hline
\end{tabular}

* N'T $=$ not tested.

$\uparrow$ Added as a suspension to give about $1 \mathrm{mg} . / \mathrm{ml}$. medium.

The following compounds supported growth of neither organism (bicarbonate present); thiocyanate, thioglycollate, butyrate, $\beta$-hydroxybutyrate, hexanoate, octanoate, glutamate, aspartate, ethanol, citrate, glucose, gluconate and mannitol.

\section{Ribulose diphosphate carboxylase activity}

The RuDP carboxylase was assayed in extracts of both organisms grown on different substrates (Table 2). Enzyme activity was high in thiosulphate-grown organisms; the specific activity of Chromatium and Thiopedia extracts was, respectively, 1000-1300 and 900-1300 units/mg. protein. RuDP carboxylase activity was demonstrated in extracts of Chromatium organisms grown on all the organic substrates tested though it was always lower than that in thiosulphategrown organisms. Pyruvate-grown Chromatium had the lowest activity and succinate-grown organisms the highest. With Thiopedia the differences in enzyme activity between organisms grown on thiosulphate and those grown on organic substrates was less marked than with Chromatium, and in the case of malate the activity was equal to that on the inorganic substrate. As with Chromatium pyruvate-grown Thiopedia organisms had the lowest activity. A definite correlation between the oxidation level of the organic substrates and RuDP carboxylase 
activity was not evident in these results. However, the fact that the carboxylase was least active in pyruvate-grown and acetate-grown organisms may be significant.

\title{
Synthesis of RuDP carboxylase by cultures of Chromatium
}

Effect of transfer from thiosulphate to pyruvate and vice versa. In these experiments Chromatium cultures on thiosulphate and on pyruvate were harvested during the logarithmic phase of growth and re-incubated, respectively, in pyruvate and thio-

\section{Table 2. RuDP carboxylase activity in Chromatium and Thiopedia organisms grown on organic substrates}

\begin{abstract}
Enzyme activities are expressed as percentage of that in extracts of thiosulphategrown organisms. The enzyme was assayed in at least two extracts from organisms grown on each substrate, the mean value being used in the calculation. The variation in activity of such replicate extracts did not exceed $15 \%$.
\end{abstract}

RuDP carboxylase activity

\begin{tabular}{|c|c|c|}
\hline \multirow[b]{2}{*}{ Substrate } & \multicolumn{2}{|c|}{ ( $\%$ that of thiosulphate organisms) } \\
\hline & Chromatium & Thiopedia \\
\hline Acetate & 41 & 45 \\
\hline Fumarate & 46 & 77 \\
\hline Succinate & 86 & 63 \\
\hline Pyruvate & 25 & 41 \\
\hline Propionate & 65 & 60 \\
\hline Malate & 37 & 100 \\
\hline Lactate & 39 & $\mathbf{5 5}$ \\
\hline Glycerol & $-*$ & 60 \\
\hline Fructose & - & 73 \\
\hline Glycollate & - & 75 \\
\hline Glyoxylate & - & 73 \\
\hline Formate & - & 91 \\
\hline
\end{tabular}

sulphate medium. Samples were taken at intervals and the carboxylase activity determined in the cell-free extracts. In these experiments the initial protein concentration was about $0.23 \mathrm{mg}$. $/ \mathrm{ml}$. and rose to $0.4-0.5 \mathrm{mg} . / \mathrm{ml}$. during the course of incubation for $10 \mathrm{hr}$. (Fig. 1). The same growth rate was observed with thiosulphate as with pyruvate.

Upon transfer of thiosulphate-grown chromatium organisms to pyruvate medium the enzyme value decreased immediately and after $10 \mathrm{hr}$. reached that normally found in pyruvate-grown organisms (Fig. 2). The rapid initial decrease in enzyme concentration was due to an apparent loss or inactivation, rather than to dilution of preformed enzyme as the culture grew. This is shown by the differential plot which expresses the amount of carboxylase $/ \mathrm{ml}$. culture as a function of the total protein/ml. (Fig. 3).

Pyruvate-grown organisms rapidly synthesized RuDP carboxylase when transferred to thiosulphate medium, finally attaining the value typical of organisms grown with this substrate (Fig. 2). The increase in carboxylase was inhibited by chloramphenicol $(0.1 \mathrm{~mm})$, suggesting that the inhibition was due to de novo formation of protein rather than to the unmasking of preformed enzyme (Fig. 2).

Effect of mixtures of thiosulphate and pyruvate. Addition of pyruvate to cultures forming $\mathrm{RuDP}$ carboxylase in response to thiosulphate caused an immediate 
cessation of enzyme synthesis (Fig. 4). However, the specific activity of the enzyme in the cell-free extracts remained constant and did not decline as was observed when organisms were transferred from thiosulphate to pyruvate. This suggested that the presence of thiosulphate prevented the loss of enzyme activity. This was confirmed by the following experiment. Thiosulphate-grown organisms were transferred to medium containing pyruvate alone, thiosulphate alone and pyruvate + low concentrations of thiosulphate. Pyruvate, thiosulphate and RuDP carboxylase

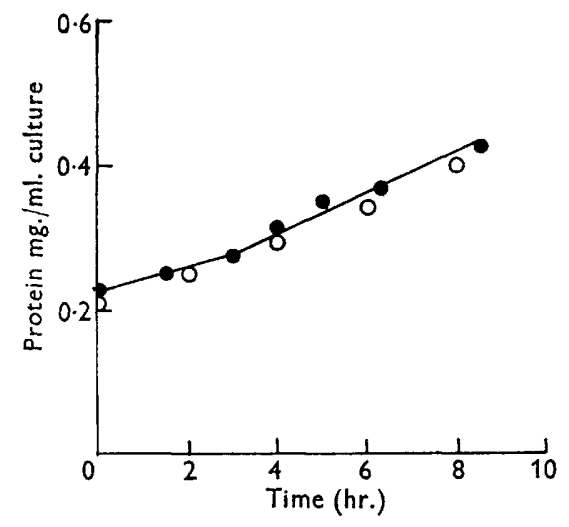

Fig. 1

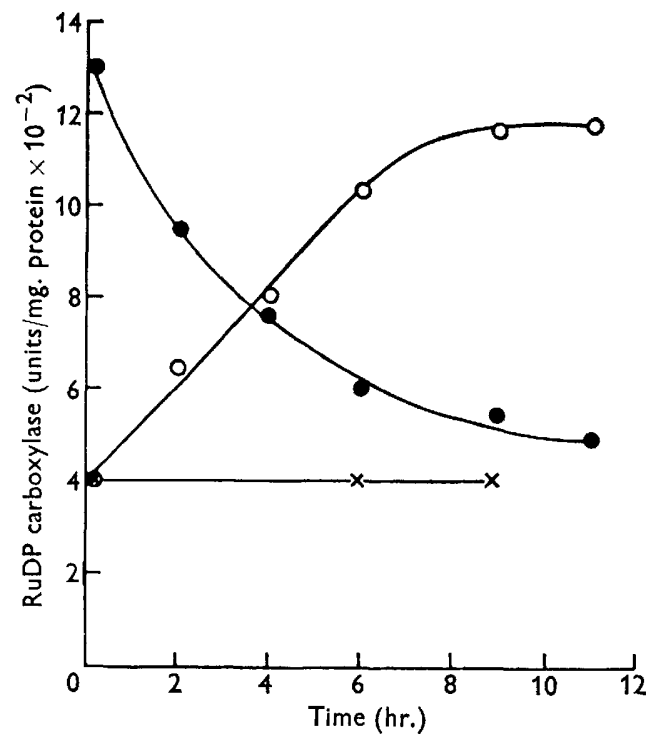

Fig. 2

Fig. 1. Growth of Chromatium organisms transferred from thiosulphate to pyruvate (- - ) and from pyruvate to thiosulphate (-O-). The concentration of substrate was 0.01 M. Growth is expressed as $\mathrm{mg}$. protein $/ \mathrm{ml}$., estimated by the biuret method.

Fig. 2. RuDP carboxylase activity in extracts of Chromatium organisms transferred from pyruvate to thiosulphate $(-\mathrm{O}-)$, from thiosulphate to pyruvate $\left(--_{-}\right)$, and from pyruvate to thiosulphate in the presence of $0.1 \mathrm{~mm}$ chloramphenicol $(x)$. Substrate concentration was $0.01 \mathrm{M}$.

activity were estimated at intervals during incubation. The organisms utilized both substrates simultaneously (Table 3). In the cultures on pyruvate only, the carboxylase activity showed the usual decline. In the presence of thiosulphate+ pyruvate, however, the enzyme value stayed constant so long as thiosulphate still remained, but enzyme activity declined when the thiosulphate had disappeared ('Table 3). In cultures on thiosulphate alone the amount of carboxylase remained constant even after all the thiosulphate had been utilized. The presence of pyruvate was therefore necessary for loss of enzyme to occur.

\section{Incorporation of ${ }^{14} \mathrm{CO}_{2}$ by Chromatium organisms}

The presence of RuDP carboxylase in organisms growing on organic carbon raises the question of whether the enzyme actually functions under these conditions. In order to function the entire reductive pentose cycle must also be presumed to 
operate since this provides the substrate for carboxylation, namely RuDP. To test this, the early products of ${ }^{14} \mathrm{CO}_{2}$ were examined by the techniques developed by Calvin and colleagues (Bassham \& Calvin, 1957). At least two criteria should be fulfilled to establish firmly the operation of the reductive pentose cycle: (1) 3-phosphoglycerate should be one of the earliest labelled compounds to appear after exposure to ${ }^{14} \mathrm{CO}_{2} ;(2)$ the relative activity of this compound should decrease with time (Quayle, 1961).

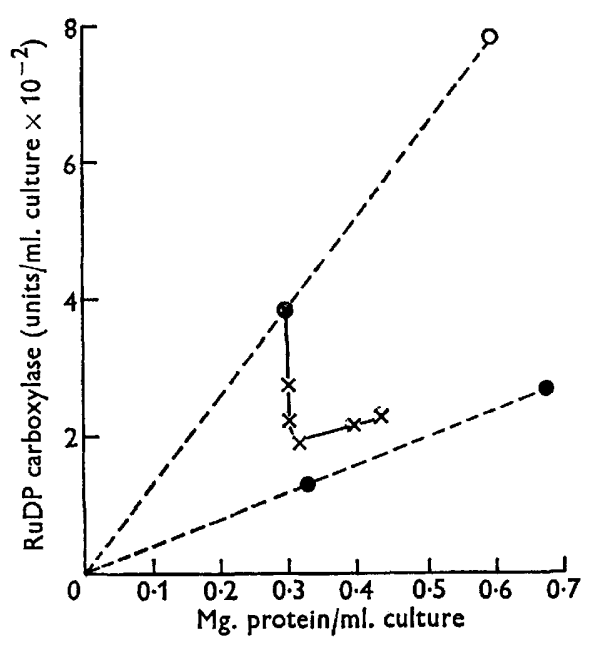

Fig. 3

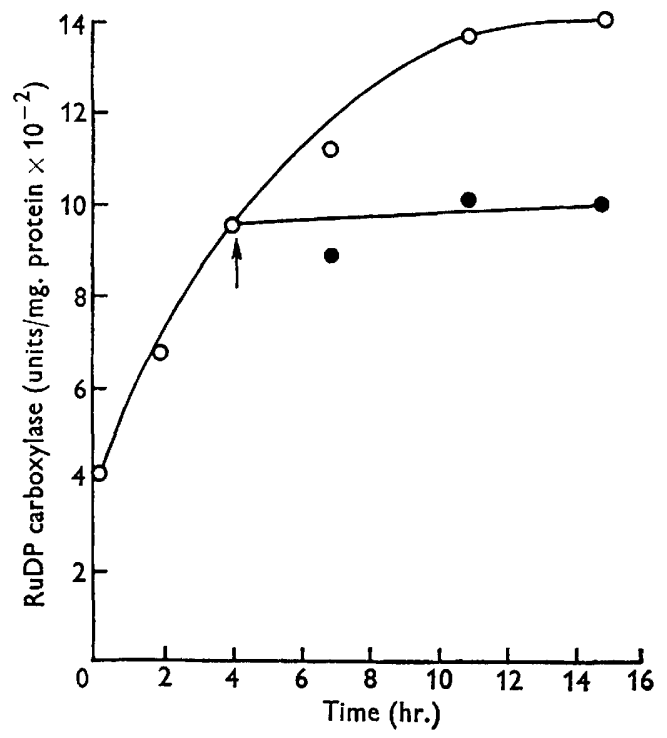

Fig. 4

Fig. 3. Loss of RuDP carboxylase upon transfer of Chromatium organisms from thiosulphate to pyruvate $(x)$. Results are shown as the differential rate of enzyme synthesis. The differential rates of synthesis are also shown for organisms transferred from thiosulphate to thiosulphate (-O-) and from pyruvate to pyruvate (-O-). Substrate concentration was $0.01 \mathrm{M}$.

Fig. 4. Effect of addition of pyruvate on RuDP carboxylase formation by Chromatium organisms. Pyruvate-grown organisms were re-incubated in thiosulphate medium and the RuDP carboxylase determined at intervals (-O-). At the point marked by the arrow pyruvate $(0.02 \mathrm{M})$ was added to one half of the culture and the RuDP carboxylase activity was determined at intervals (- - - )

Incorporation of ${ }^{14} \mathrm{CO}_{2}$ under autotrophic and heterotrophic conditions. Organisms grown on thiosulphate or pyruvate were exposed to ${ }^{14} \mathrm{CO}_{2}$ in the presence of their original substrate and the pattern of incorporation followed. Incorporation into the ethanol-soluble fraction occurred at a linear rate up to $3 \mathrm{~min}$. with suspensions on thiosulphate (Fig. 5). In the presence of thiosulphate the phosphate esters and aspartate were the first labelled-products detected by radio-autography. In the earliest samples about $80 \%$ of the total ${ }^{14} \mathrm{CO}_{2}$ fixed was in the form of phosphate esters (at the origins of the chromatograms) and their proportion, unlike that of other labelled-products, decreased with time (Fig. 6). Chromatography after dephosphorylation of the esters formed in the early stages showed that 3-phosphoglycerate accounted for over $80 \%$ of the labelled phosphorylated compounds. These 
results were similar to those of Fuller et al. (1961) except that they found a higher proportion of aspartate in the early samples and that incorporation into aspartate and into phosphate esters showed a negative slope with time.

\section{Table 3. RuDP carboxylase in cultures of Chromatium growing with mixtures of pyruvate and thiosulphate}

Chromatium organisms were harvested after growth on thiosulphate and resuspended in medium containing various mixtures of pyruvate and thiosulphate. The cultures were incubated at $30-32^{\circ}$ in the light under nitrogen and sampled at intervals for analysis of pyruvate, thiosulphate and RuDP carboxylase. Pyruvate and thiosulphate are expressed as $\mu \mathrm{mole} / \mathrm{ml}$. and carboxylase activity as units $/ \mathrm{mg}$. protein.

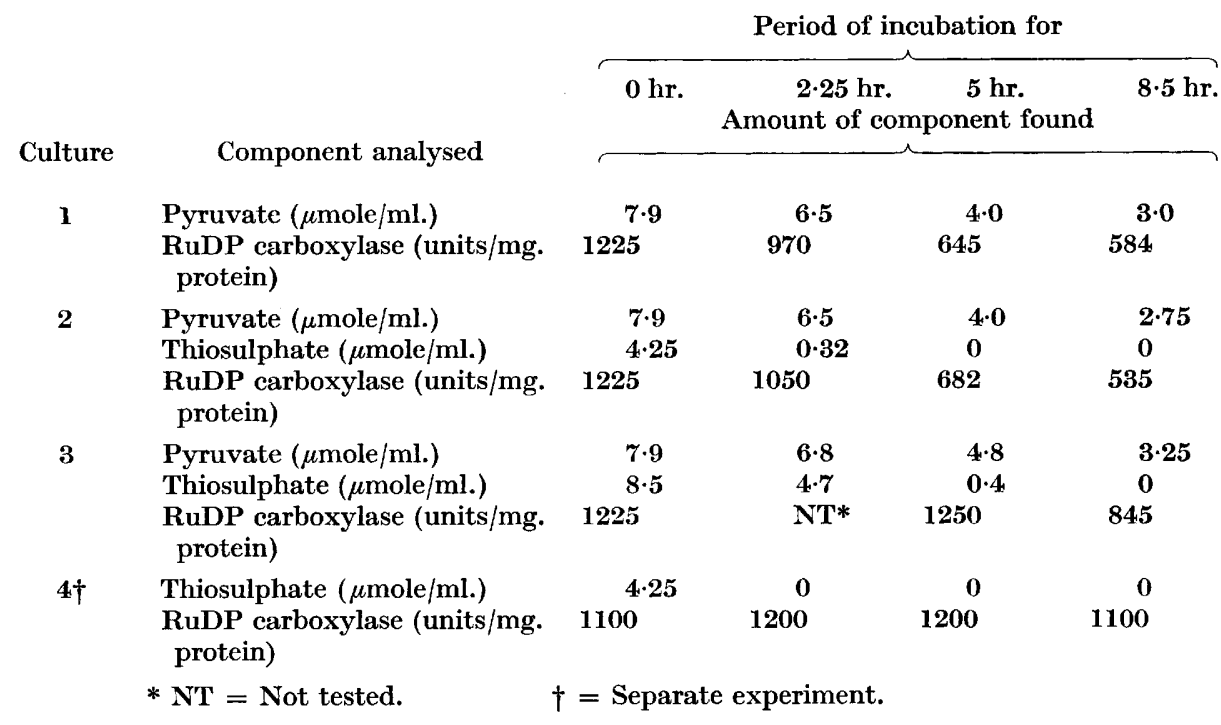

With pyruvate as substrate, the initial rate of incorporation was higher than that finally attained (Fig. 5). This might suggest that ${ }^{14} \mathrm{CO}_{2}$ was incorporated by two routes, one leading to a small pool of compounds which became rapidly saturated with ${ }^{14} \mathrm{C}$, and the other leading to a larger pool which became labelled more slowly. Alternatively, the ${ }^{14} \mathrm{CO}_{2}$ might have been rapidly incorporated into compounds which were then further metabolized at a slower rate. The amount of ${ }^{14} \mathrm{CO}_{2}$ incorporated in presence of pyruvate was about $10 \%$ of that incorporated in presence of thiosulphate. This was probably due in part, at least, to dilution with unlabelled $\mathrm{CO}_{2}$ formed as a result of pyruvate metabolism.

In the presence of pyruvate the first labelled products to be detected were, again, phosphate esters and aspartate, but in contrast to the results with thiosulphate, over $90 \%$ of the ${ }^{14} \mathrm{C}$ fixed initially was in the aspartate. This compound was the only ethanol-soluble component to show a negative slope (Fig. 6). About 64\% of the phosphate esters consisted of 3-phosphoglyceric acid, identified by chromatography after dephosphorylation (Fig. 6).

The results suggest that in the presence of thiosulphate, ${ }^{14} \mathrm{CO}_{2}$ was fixed primarily via 3-phosphoglycerate, presumably as a result of RuDP carboxylase action, and with pyruvate present, fixation was predominantly via a carboxylation leading to a 4-C product. However, the fact that 3-phosphoglycerate became labelled during 
the earliest stages indicated that the RuDP carboxylase and the reductive pentose cycle were functioning to some extent.

With succinate-grown organisms incubated with succinate and ${ }^{14} \mathrm{CO}_{2}$, the earliest

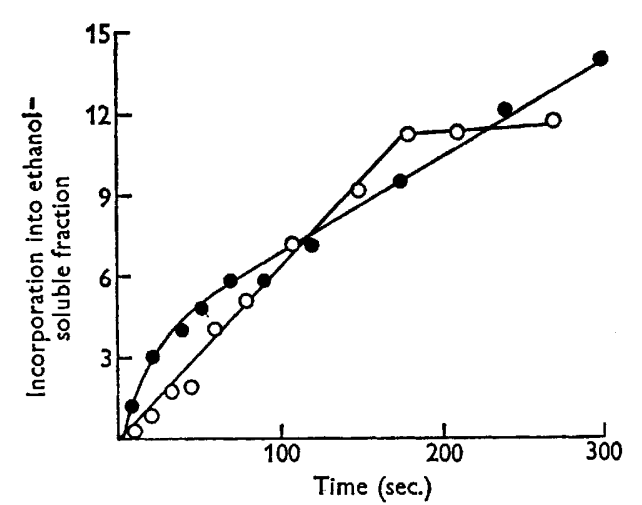

Fig. 5

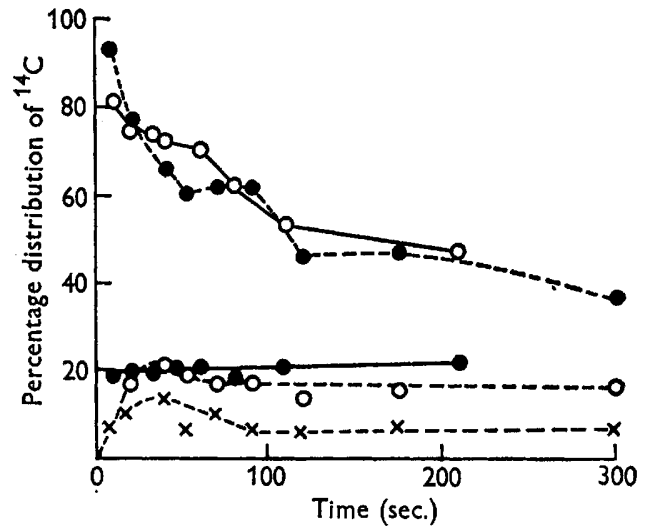

Fig. 6

Fig. 5. Time course of incorporation of ${ }^{14} \mathrm{CO}_{2}$ into the ethanol-soluble fraction of Chromatium. Incorporation was followed with organisms grown on thiosulphate $(-\mathrm{O}-)$ and pyruvate (-O-) incubated anaerobically in the light with the same substrates plus $\mathrm{Na}_{2}{ }^{14} \mathrm{CO}_{3}$ (see Methods). Results are shown as counts per min. $\times 10^{-3}$ (thiosulphate) or $10^{-2}$ (pyruvate) incorporated into the ethanol-soluble fraction per $\mathrm{mg}$. dry wt. of organisms.

Fig. 6. Time course of incorporation of $\mathrm{Na}_{2}{ }^{14} \mathrm{CO}_{3}$ into components of the ethanol-soluble fraction of Chromatium. Thiosulphate- $(-)$ and pyruvate-grown (-- ) organisms were incubated anaerobically in the light with the same substrates plus $\mathrm{Na}_{2}{ }^{14} \mathrm{CO}_{3}$. Glyceric acid was identified chromatographically after dephosphorylation of the phosphate esters. $O$, Phosphate esters; 0 , aspartate; $\times$, glyceric acid.

Table 4. Incorporation of ${ }^{14} \mathrm{CO}_{2}$ into phosphoglycerate by thiosulphate-

$$
\text { grown Chromatium organisms }
$$

Thiosulphate-grown Chromatium organisms (equiv. $4 \mathrm{mg}$. dry wt.) were suspended in a final volume of $1.5 \mathrm{ml}$. in a mixture containing ( $\mu$ mole): potassium phosphate

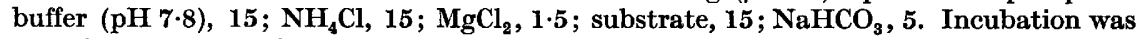
at $30^{\circ}$ in an atmosphere of nitrogen in 25 ml. rubber-capped Erlenmeyer flasks. After shaking for $5 \mathrm{~min}$. at $30^{\circ}$ in the light $\mathrm{Na}_{2}{ }^{14} \mathrm{CO}_{3}(40 \mu \mathrm{c})$ was added with a hypodermic syringe. The reaction was stopped by adding $4 \mathrm{ml}$. ethanol + water + acetic acid (see Methods); the ethanol-soluble fraction was prepared for radio-autography, but was treated directly with Polidase-s before applying to the chromatograms. Besides glyceric acid, other radioactive areas on the chromatograms corresponded mainly to aspartic, malic and glutamic acids and to sugars.

$\begin{array}{lccc}\text { Substrate } & \text { Time }(\mathrm{sec}) & \begin{array}{c}\text { in ethanol-soluble } \\ \text { fraction }\left(\mathrm{cpm} \times 10^{-3}\right)\end{array} & \begin{array}{c}\text { fixed in } \\ \text { glyceric acid }\end{array} \\ \text { None } & 24 & 7 \cdot 6 & 37 \\ \text { Thiosulphate } & 14 & 38 & 67 \\ \text { Pyruvate } & 23 & 73 & 59 \\ & 14 & 12 \cdot 2 & 25 \\ \text { Acetate } & 22 & 21 \cdot 7 & 22 \\ & 15 & 10 \cdot 7 & 34 \\ \text { Succinate } & 23 & 16 \cdot 9 & 15 \\ & 14 & 8 \cdot 1 & 25 \\ & 23 & 23 & 35\end{array}$


sample (15 sec.) showed that phosphate esters accounted for $45 \%$ of the total ${ }^{14} \mathrm{C}$ incorporated into the ethanol-soluble fraction. Of the other labelled compounds detected, most $(44 \%$ of the total) was in the aspartate + malate + glutamate areas of the chromatograms. The early and relatively high incorporation of ${ }^{14} \mathrm{CO}_{2}$ into the phosphate esters suggested that the RuDP carboxylase was functioning in the presence of succinate; it appeared to be more active than with pyruvate as substrate.

Incorporation by thiosulphate-grown organisms in the presence of organic substrates. In these experiments thiosulphate-grown organisms, containing high concentrations of $\mathrm{RuDP}$ carboxylase, were incubated with ${ }^{14} \mathrm{CO}_{2}$ or various organic substrates. Samples were taken only after short intervals of time, and before chromatography they were treated with Polidases to hydrolyse the phosphate esters. Results are expressed as the percentage isotope found in the glyceric acid derived by hydrolysis of 3-phosphoglycerate. With all the organic substrates tested glyceric acid accounted for at least $20 \%$ of the total ${ }^{14} \mathrm{CO}_{2}$ fixed in the early stages of exposure to the isotope. The only conclusion that can be drawn from these observations is that the organic substrates did not prevent the $\mathrm{RuDP}$ carboxylase and the reductive pentose cycle from functioning. The possibility that some organic substrates may partially inhibit the action of RuDP carboxylase cannot be demonstrated in experiments of this type. Complicating factors which obscure the interpretation include differences in the rate of metabolism of the various substrates to give unlabelled $\mathrm{CO}_{2}$.

Table 5. Incorporation of ${ }^{14} \mathrm{CO}_{2}$ into phosphate esters by pyruvategrown Chromatium

Pyruvate-grown organisms were exposed to $\mathrm{Na}_{2}{ }^{14} \mathrm{CO}_{3}$ with $0 \cdot 01 \mathrm{M}$-thiosulphate and/or $0.01 \mathrm{~m}-$ pyruvate under the conditions described in Table 4 . The exposure time was 11 sec. in each case. The ethanol-soluble fraction was subjected to radio-autography without Polidase-s treatment.

$\begin{array}{lc} & \begin{array}{c}\% \text { of total }{ }^{14} \mathrm{C} \\ \text { found fixed in } \\ \text { Substrate }\end{array} \\ \text { phosphate esters }\end{array}$

Incorporation by pyruvate-grown Chromatium organisms in the presence of thiosulphate and pyruvate. In these experiments pyruvate-grown Chromatium organisms were incubated with ${ }^{14} \mathrm{CO}_{2}$ with pyruvate or thiosulphate alone, or both together. The earliest samples showed considerable incorporation of ${ }^{14} \mathrm{C}$ into the phosphate esters with thiosulphate alone, and only slight incorporation with pyruvate alone (Table 5). However, with thiosulphate + pyruvate there was again considerable incorporation into the phosphate esters. This suggests that electron flow due to the metabolism of thiosulphate increased the rate of $\mathrm{CO}_{2}$ fixation via the reductive pentose cycle, even in the presence of pyruvate.

\section{- DISCUSSION}

The fact that the concentration of RuDP carboxylase in Chromatium and Thiopedia organisms varied with the substrate upon which the organisms had been grown shows that this enzyme was subject to metabolic control. It was highest in 
organisms grown with thiosulphate $+\mathrm{CO}_{2}$; this was to be expected because of the key role of RuDP carboxylase in the reductive pentose cycle. The enzyme was also present, though less active, in organisms grown with organic carbon. Thus, organic substrates only partially repressed the enzyme, whereas in those non-photosynthetic facultative autotrophs examined so far, organic substrates cause virtually complete repression (Quayle, 1961).

In Athiorhodaceae RuDP carboxylase is formed by cultures growing on organic substrates anaerobically in the light, but the enzyme is repressed by oxygen (Lascelles, 1960b). This suggests that the enzyme may function under anaerobic conditions in making $\mathrm{CO}_{2}$ available as an outlet for excess reducing power. No definite correlation was found in the present work between the reduction level of the substrates and the concentration of the RuDP carboxylase in the organisms. If the enzyme does play a part in removing excess reducing power in organisms growing anaerobically in the light, it is conceivable that the concentration of a reduced electron carrier(s) in the electron transport chain might regulate the rate of enzyme synthesis. This would depend on the rate at which the substrate is metabolized, as well as on the reduction level of the substrate. Experiments with cultures growing at a fixed rate in continuous culture might provide a clearer picture of effects of different substrates on the rate of carboxylase formation.

It is not possible to tell from the present work whether reduced sulphur compounds actually induce synthesis of RuDP carboxylase since both Chromatium and Thiopedia need reduced sulphur (sulphide or thiosulphate) as source of cell sulphur. Hence in all experiments with organic substrates, low concentrations of sulphide were present in the medium. The immediate increase in carboxylase observed when pyruvate-grown cultures of Chromatium are transferred to thiosulphate might suggest that thiosulphate is an inducer. However, this might also be interpreted as being due to metabolism of thiosulphate altering the level of the hypothetical reduced carrier(s) which may in turn regulate the rate of enzyme formation. The fact that thiosulphate increases the rate of $\mathrm{CO}_{2}$ fixation via the reductive pentose cycle even in the presence of pyruvate (Table 5) suggests that its metabolism does increase the level of reducing power in the organisms.

When cultures of Chromatium, initially high in RuDP carboxylase, are transferred from thiosulphate to pyruvate medium the enzyme is, apparently, partially destroyed. The loss of enzyme activity is far greater than can be accounted for by dilution of preformed enzyme as the organism grows. In Pseudomonas oxalaticus and Micrococcus denitrificans the preformed enzyme is diluted out, but there is no destruction on transfer to media which do not promote RuDP carboxylase formation (Quayle \& Keech, 1959; Kornberg, Collins \& Bigley, 1960). Loss of activity of other adaptive enzymes, due apparently to preferential destruction or turnover, has been observed with $\delta$-aminolaevulate synthetase in Rhodopseudomonas spheroides (Lascelles, $1960 \mathrm{a}$ ), and with glycerol dehydrogenase in Aerobacter aerogenes (Lin, Levin $\&$ Magasanik, 1960). The fact that the concentration of RuDP carboxylase remains constant in Chromatium so long as thiosulphate is present (Fig. 3; Table 3) suggests that thiosulphate exerts a protective effect, or that with thiosulphate present the rate of enzyme synthesis is balanced by its rate of breakdown.

Evidence that the reductive pentose cycle does function when Thiorhodaceae are grown on organic substrates is provided by the observations that under these 
conditions RuDP carboxylase is formed, and phosphate esters are early products of ${ }^{14} \mathrm{CO}_{2}$ fixation. The isotope experiments do not permit a quantitative assessment of the extent to which the cycle operates with the various substrates. This would require with each substrate knowledge of the pool concentrations of labelled intermediates and of the dilution of the ${ }^{14} \mathrm{CO}_{2}$ with unlabelled $\mathrm{CO}_{2}$ from the metabolism of the substrate.

The results support the view that the reductive pentose cycle performs two functions in the Thiorhodaceae examined: (1) to provide cell carbon from $\mathrm{CO}_{2}$ when growth is under autotrophic conditions: (2) to provide an outlet for excess reducing power formed as a result of substrate oxidation. These possible functions must be kept in mind when considering mechanisms for regulating synthesis of RuDP carboxylase.

We are greatly indebted to Dr D. Hoare, Dr P. Large and Dr R. Quayle for invaluable advice on the design and interpretation of radio-autotrophic experiments. One of us (R.E.H.) held a Postdoctoral Fellowship (No. 9186) from the National Institute of General Medical Sciences during this work which was assisted by grants to the Department from the Rockefeller Foundation and the United States Department of Health, Education and Welfare.

\section{REFERENCES}

Bassham, J. A. \& Calvin, M. (1957). The Path of Carbon in Photosynthesis. Englewood Cliffe, N. J.: Prentice-Hall Inc.

Benson, A. A., Bassham, J. A. \& Calvin, M. (1951). Sedoheptulose in photosynthesis by plants. J. Amer. chem. Soc. 73, 2970.

Friednann, T. E. \& Haugen, G. E. (1943). Pyruvic acid. II. Determination of keto acids in blood and urine. J. biol. Chem. 147, 415 .

Fuller, R. C., Smillie, R. M., Sisler, E. C. \& Kornberg, H. L. (1961). Carbon metabolism in Chromatium. J. biol. Chem. 236, 2140.

Gaffron, H. (1935). Über den Stoffwechsel der Purpurbakterien. 2. Biochem. Z. 275, 301.

Hoare, D. E. (1963). The photoassimilation of acetate by Rhodospirillum rubrum. Biochem. J. 87, 284.

KNIGHT, M. (1962). The photometabolism of propionate by Rhodospirillum rubrum. Biochem. J. 83, 170.

Kohlmiller, E. F. \& Gest, H. (1951). A comparative study of the light and dark fermentations of organic acids by Rhodospirillum rubrum. J. Bact. 61, 269.

Kornberg, H. L., Collins, J. F. \& Bigley, D. (1960). Influence of growth substrates on metabolic pathways in Micrococcus denitrificans. Biochim. biophys. Acta, 39, 9.

Large, P. J., Peel, D. \& Quayle, J. R. (1961). Microbial growth on $C_{1}$ compounds. 2. Synthesis of cell constituents by methanol and formate-grown Pseudomonas AM-1, and methanol-grown Hyphomicrobium vulgare. Biochem. J. 81, 470.

LARSEN, H. (1952). On the culture and general physiology of the green sulfur bacteria. J. Bact. 64, 187.

LASCELles, J. $(1960 a)$. The synthesis of enzymes concerned in bacteriochlorophyll formation in growing cultures of Rhodopseudomonas spheroides. J. gen. Microbiol. 23, 487.

LASCELIES, J. (1960b). The formation of ribulose 1:5-diphosphate carboxylase by growing cultures of Athiorhodaceae. J. gen. Microbiol. 23, 499.

Lin, E. C. C., Levin, A. P. \& Magasanik, B. (1960). Effect of aerobic metabolism on the inducible glycerol dehydrogenase of Aerobacter aerogenes. J. biol. Chem. 235, 1824. 
Losada, M., Trebst, A. V., Ogata, S. \& Arnon, D. I. (1960). Equivalence of light and adenosine triphosphate in bacterial photosynthesis. Nature, Lond. 186, 753.

Lowry, O. H., Rosebrough, N. J., Farr, A. L. \& Randall, R. J. (1951). Protein measurement with the folin phenol reagent. J. biol. Chem. 193, 365.

MULLER, F. M. (1933). On the metabolism of the purple sulphur bacteria in organic media. Arch. Mikrobiol. 4, 131.

QUAYLE, J. R. (1961). Metabolism of $\mathrm{C}_{1}$ compounds in autotrophic and heterotrophic micro-organisms. Annu. Rev. Microbiol. 15, 119.

Quayle, J. R. \& Keech, D. B. (1959). Carbon assimilation by Pseudomonas oxalaticus $(\mathrm{OXI})$. 3. Oxalate utilization during growth on oxalate. Biochem. $J .75,515$.

Stanier, R. Y. (1961). Photosynthetic mechanisms in bacteria and plants: development of a unitary concept. Bact. Rev. 25, 1.

van Niel, C. B. (1936). On the metabolism of the Thiorhodaceae. Arch. Mikrobiol. 7, 323. van Niel, C. B. (1941). Bacterial photosynthesis. Advanc. Enzymol. 1, 263. 